\title{
As (in)diferenças sociais nas vozes poéticas de Alda Espírito Santo e Noémia de Sousa
}

\author{
Érica Antunes Pereira ${ }^{1}$
}

\begin{abstract}
RESUMO: Amparados pelos estudos de Frantz Fanon (1979) e Albert Memmi (1989), pretendemos analisar os poemas "Passe" de Noémia de Sousa e "Construir" de Alda Espírito Santo a fim de demonstrar a preocupação dessas autoras no que diz respeito às (in)diferenças sociais.

ABSTRACT: Starting from the studies of Frantz Fanon (1979) and of Albert Memmi (1989), we intend to analyze the poems "Passe" of Noémia de Sousa and "Construir" of Alda Espírito Santo in order to demonstrate those author's concern on the social (in)differences.
\end{abstract}

PALAVRAS-CHAVE: Literaturas Africanas de Língua Portuguesa; Poesia engajada; Alda Espírito Santo; Noémia de Sousa

KEYWORDS: African Literatures of Portuguese Language; Engagée poetry; Alda Espírito Santo; Noémia de Sousa.

Nascidas em 1926, a são-tomense Alda Espírito Santo e a moçambicana Noémia de Sousa se tornaram figuras exponenciais das literaturas africanas de língua portuguesa tanto pela qualidade estética de sua poesia quanto por denunciarem a situação colonial desde o fim dos anos 40, dando voz aos oprimidos e numa postura que advém das (in)diferenças e das injustiças sociais experimentadas pelas autoras desde muito cedo. Noémia de Sousa, por exemplo, fala sobre sua "tomada de consciência" em entrevista concedida a Michel Laban (1998), merecendo destaque duas passagens:

E eu lembro-me de uma vez estar num autocarro, num machimbombo, como se chama lá [em Moçambique], a ler um livro e um "senhor" troçar de mim. Foi uma coisa, eu era uma criança, devia ter para aí dez anos, que me chocou muito, tanto mais que se me dirigiu macaqueando a pronúncia do negro a falar português, com um forte sotaque, a insinuar que eu não sabia ler e que estava a fingir para mostrar aos brancos. Eu era uma miúda e ele chocou-me, está a ver? (p. 267)

Mesmo na igreja o negro tinha que ficar lá para trás, nos bancos de trás; nos autocarros, aquele banco corrido, assim de trás, era para eles, não podiam vir à frente. Nós éramos descendentes de colonos, nós mestiços tínhamos direito a ficar

\footnotetext{
${ }^{1}$ Doutoranda em Estudos Comparados de Literaturas de Língua Portuguesa na Universidade de São Paulo (USP). Pesquisa: Da catana ao batom: Diferentes perspectivas da representação do feminino na poesia africana de língua portuguesa - análise das obras de Alda Espírito Santo, Alda Lara, Conceição Lima, Glória de Sant'Anna, Noémia de Sousa e Paula Tavares. E-mail: erica.antunes@gmail.com.
} 
em qualquer lugar, mas eu via os outros lá atrás. Eu via a mulher grávida negra que ficava de pé e se não fosse um dos negros a dar-lhe o lugar ninguém lhe dava; mas a senhora branca que entrava, tinha logo, fosse quem fosse, alguém que se levantasse para lhe dar o lugar, grávida ou não grávida... (p. 268-269)

Também Alda Espírito Santo, em entrevista ao mesmo Michel Laban (2002, p. 67), afirma:

... eu cresci, durante uns oito anos, num colégio de freiras, no norte de Portugal, e só quando a minha mãe chegou a Portugal e nos levou - eu e a minha irmã - para Lisboa, encontrei um grupo de parentes e amigos africanos. Lá no Norte de Portugal havia poucos negros. Na rua diziam-nos: "Preta, mulata, nariz de macaca" e por aí fora outras coisas disparatadas, mas felizmente nada disso me afectou.

Depois é que tomamos contacto com o mundo, Tínhamos um primo chamado Arlindo Espírito Santo que andava à descoberta das pessoas! Ele é que nos levou o Mário de Andrade, o Agostinho Neto - todo o mundo com que entrámos em contacto. Foi toda uma descoberta que nos levou a tomar consciência de nós mesmos.

Esse sentimento de injustiça suscitado na infância das duas autoras se acentuou com o correr dos anos e deu passagem, no final da década de 40, ao que Roberto Pontes (1999, p. 30) chamou de "poesia insubmissa", caracterizada por conter "um tom de luta e libertação" capaz de "modificar [o] comportamento coletivo, ainda que por um instante".

No início da década de 50, Alda Espírito Santo e Noémia de Sousa se conheceram em Lisboa, no número 37 da Rua Actor Vale², ou, simplesmente, na casa da Tia Andreza, como ficou conhecida a morada da família Espírito Santo que, ao abrir as portas aos então jovens intelectuais africanos, "permitiu a aproximação de gerações e a transmissão de um caldo de cultura em vias de se perder" (MOURÃO, 1997, p. 125). Isso porque o objetivo dos estudos junto ao Centro de Estudos Africanos, como passou a ser conhecido o grupo realizador das tertúlias, era

o retorno às fontes, a redescoberta do Eu africano, a reafricanização de assimilados que eles eram de facto, a tomada de consciência da total alienação, pelo facto de terem sido os pouco eleitos 'portugalizados' que conseguiram ultrapassar todas as barreiras e atingir a suprema etapa do ingresso nas universidades portuguesas (ROCHA, 2003, p. 89).

\footnotetext{
${ }^{2}$ A respeito da ocasião, Alda Espírito Santo escreve: “Tivemos conhecimento da chegada de Noémia de Sousa a Portugal e logo nos pusemos em contacto com ela. De pronto, uma tarde, Noémia entrava serenamente na residência da Actor Vale-37 e, para sempre, uma amizade segura nos uniu" (2006, p. 47).
} 
Difundiu-se, assim, o "discurso da diferença” característico da Negritude africana de língua portuguesa e que, segundo Pires Laranjeira (1995, p. 17; 498), foi a "única corrente estético-literária que deu expressão ao homem negro considerado no seu conjunto e universalidade" naquele período. Alda Espírito Santo e Noémia de Sousa fizeram parte dessa geração de 50 e contribuíram quer para a (re)afirmação dos valores africanos, quer como fomentadoras da luta pela independência que começava a brotar. Isso porque, à medida que a representação desse homem negro e colonizado ocorria e se acentuavam as diferenças em relação ao branco colonizador, tornava-se possível cogitar no "enraizamento e autonomia das respectivas literaturas" (LARANJEIRA, 1995, p. 503), pois "quem tem o poder de representar tem o poder de definir e determinar a identidade" (SILVA, 2005, p. 91).

Seguindo essa senda, observamos que a poesia dessas duas autoras contém um alto teor de denúncia das (in)diferenças sociais, entendidas por nós como um processo dialético que, a partir da perspectiva de um sujeito poético colonizado, realça: a) a diferença social experimentada pelo colonizado - descrito, nesse caso, a partir do uso de adjetivos que possuem conotação negativa (“despojado", "escorraçado", entre outros) -, diante de uma situação fática que, normalmente, está ligada ao processo de colonização; e, b) a indiferença do colonizador quanto à sorte do colonizado, mas numa esfera que pende para a ideal - e que, talvez, quem sabe, não corresponda à ótica do colonizador, tido como aquele que se "esquece" do outro "na hora do banquete" ou como "o carrasco" que não se digna a ensaiar o menor gesto de bondade -, pois o ponto de vista do sujeito poético é sempre parcial, ou seja, é a perspectiva do colonizado a tomada como válida e verdadeira nos poemas das autoras em apreço.

Para termos uma noção mais acurada de tal fato, vejamos de perto dois poemas que bem ilustram as (in)diferenças sociais, a começar por "Passe" de Noémia de Sousa (2001, p. 41-43). Datado de 6 de setembro de 1950, este poema dá, como dissemos há pouco, voz ao colonizado, então considerado "indígena", para contestar a exigência de apresentar o "passe", documento que continha uma espécie de histórico pessoal em que eram anotados os trabalhos prestados e os castigos sofridos, caso houvesse ${ }^{3}$, pelo colonizado:

\footnotetext{
${ }^{3}$ Em entrevista a Michel Laban (1998, p. 315), Noémia de Sousa explica o significado do "passe" como "uma espécie de caderneta, quer dizer identificação da pessoa e depois, por todos os sítios onde ele ia trabalhando, os patrões iam pondo anotações: se o mandavam ao posto para ser castigado, era lá registado. De maneira que se se desse uma má informação num passe, nunca mais podia arranjar trabalho, não é?”
} 


\section{Passe}

A ti, que nos exiges um passe para podermos passear

pelos caminhos hostis da nossa terra,

diremos quem somos, diremos quem somos:

- Eternos esquecidos na hora do banquete, abandonam-nos sempre na rua húmida, reluzente de noite, e oferecem-nos apenas o espectáculo das janelas iluminadas, dos risos estrídulos, e a amarga ironia das nossas canções negras filtradas como aguardente de cana por lábios finos e cruéis...

Nós somos os filhos adoptivos e os ilegítimos, que vossos corações tímidos, desejosos de comprar o céu - ou a vida, vieram arrancar aos trilhos ladeados de micaias, para depois nos lançarem, despidos das peles e das azagaias, - ah, despojados dos diamantes do solo e do marfim, despojados da nossa profunda consciência de homens nos tantos metros quadros ${ }^{4}$ dos bairros de zinco e caniço!

Nós somos sombras para os vossos olhos, somos fantasmas. Mas, como estamos vivos, extraordinariamente vivos e despertos! Com sonhos de melodia no fundo dos olhos abertos, somos muchopes de penas saudosas nos chapéus de lixo; e zampunganas trágicos - xipócués vagos nas noites munhuanenses, e mamparras coroados de esperança, e magaíças, e macambúzios com seu shipalapala ecoando chamamentos...

No cais da cidade, somos os pachiças e na Vida digna, somos aqueles que encontraram os lugares tomados, somos os que não têm lugar na Vida, ah na Vida que se abre, luminosa, com cada dia de pétala!

Nós somos aqueles que só na revolta encontram refúgio. Que se deixam possuir, ébrios, pelo feitiço dos tambores, nos batuques nocturnos da vingança, somos aqueles que modelam sua dor de braços torcidos no pau preto do Norte, a dor deformadora que mais tarde despertará o desprezo e a incompreensão nas prateleiras dos museus da civilização...

Somos os despojados, somos os despojados!

Aqueles a quem tudo foi roubado, Pátria e dignidade, Mãe e riquezas e crenças, e Liberdade!

Até a voz da nossa Raça, da revolta dos nossos corpos tatuados, nos foi roubada para embriaguez de vossos sentidos anémicos, arrastando-se nos bailes frios iluminados a electricidade...

Despojados, ficámos nus e trémulos, nus na abjecta escravidão dos séculos...

${ }^{4}$ Cremos que, aqui, o correto seria "quadrados", mas optamos por transcrever exatamente como aparece na edição de Sangue negro de 2001. 
Mas com o calor da chama eterna das nossas fogueiras acesas, crepitando, rubras, sobre os dias e as noites, com vaga-lumes de protesto, de gritos, de esperança!

- Agora, que sabes quem somos, não nos exijas mais a ignomínia do "passe" das vossas leis!

O sujeito poético, em "Passe", é um "nós" que, dirigindo-se a um interlocutor - o colonizador -, dá-se a conhecer e manifesta sua consciência e indignação quanto aos desmandos impostos por aquele. O tom é, de certa forma, agressivo, irônico, e pode ser constatado, na tessitura do poema, pela reiteração e pela sonoridade revelada pelos muitos “ss" - "passe", "passear", "nossa", "somos" são alguns exemplos - indicativos de uma “poética da voz" que escapa "ao exílio silencioso da escrita” (LEITE, 1998, p. 107).

Logo na primeira estrofe, valendo-se do pronome possessivo "nossa" para qualificar a terra, esse sujeito poético inaugura uma via contestatória que subverte os fatos e põe o colonizador em seu devido lugar: um lugar que, certamente, não cabe na "nossa terra"! Tanto essa idéia tem fundamento que vários recursos utilizados no poema, como os versos extensos e os sinais de pontuação, insinuam, para além do discurso narrativo, a fala proferida em público, típica das "bocas malditas", ou seja, das tribunas livres, dos espaços dedicados às denúncias e aos protestos.

Nesse sentido, ao se definir como os "eternos esquecidos na hora do banquete", o "nós" põe em xeque tanto as diferenças quanto as indiferenças sociais: se, por um lado, há "um banquete", pelo outro, há os "eternos esquecidos", os abandonados "sempre na rua húmida, reluzente de noite". As oposições constituem a base do poema conforme a figura do colonizador aparece descrita com toques de uma luminosidade que não é compartilhada pelo colonizado. No entanto, antes que imaginemos que este esteja em total desvantagem, lembremos da reversão da negatividade em positividade e vice-versa de que tão bem trata Albert Memmi (1989, p. 117-120) para perceber que, em "Passe", os signos luminosos, cuja simbologia costuma ser ligada à bondade, adquirem perspectiva absolutamente contrária, prestando-se para assinalar, como aludimos há pouco, tanto a crueza indiferente do colonizador quanto a diferença social havida entre ele e o colonizado.

Eleger o "nós" como sujeito poético, portanto, é uma estratégia bastante significativa, pois estabelece uma relação interdependente entre a coletividade e a subjetividade que, como analisa Laura Cavalcante Padilha (2002, p. 185), faz com que "o desejo de transformação" seja "mostrado como um desejo de todos, o que o torna mais 
ameaçador". Em tal aspecto, é emblemática a penúltima estrofe que, ao enunciar "Somos os despojados, somos os despojados!", irrompe de vez o grito, dando voz, ainda que subsista o teor subjetivo, à coletividade.

Nessa mesma estrofe, o par opositivo luminosidade versus obscuridade é pungente e reitera o que afirmamos há pouco quanto à assunção de significado diverso do habitual: os bailes do colonizador passam a ser tachados como "frios iluminados a electricidade" e, apesar do despojamento, da nudez e do medo imposto ao colonizado, este subverte a ordem para manter "o calor da chama eterna das nossas fogueiras acesas, / crepitando, rubras, sobre os dias e as noites,/ com vaga-lumes de protesto, de gritos, de esperança!"

Em outras palavras, ao afirmar, de modo recorrente, "Nós somos" ou, apenas, "Somos", o sujeito poético cria uma identidade opositora à identidade do colonizador, pois, modificando a perspectiva do olhar que, até então, era o do "outro", (re)conhece-se a si próprio. Por conseqüência, se pensarmos que a toda identidade corresponde uma diferença, logo vemos que esse é um processo dinâmico cuja significação se ampara nas relações de poder, na disputa contínua para mantê-lo ou conquistá-lo. É exatamente essa vontade de reivindicar o próprio espaço, a própria identidade, que observamos nos dois versos que desfecham o poema: “- Agora, que sabes quem somos,/ não nos exijas mais a ignomínia do 'passe' das vossas leis!”

O poema "Construir" de Alda Espírito Santo (2006a, p. 65), tal qual o de Noémia de Sousa, foi escrito em 1950 e focaliza as (in)diferenças sociais sob a perspectiva da coletividade. Vejamos:

\section{Construir}

Construir sobre a fachada do luar das nossas terras

Um mundo novo onde o amor campeia, unindo os homens

de todas as terras

Por sobre os recalques, os ódios e as incompreensões,

as torturas de todas as eras

É um longo caminho a percorrer no mundo dos homens.

É difícil sim, percorrer este longo caminho

De longe de toda a África martirizada.

Crucificada todos os dias na alma dos seus filhos.

É difícil sim, recordar o pai esbofeteado

Pelo despotismo dum tirano qualquer

A irmã violada pelo mais forte, os irmãos morrendo nas minas

Enquanto os argentários amontoam o oiro

É difícil sim percorrer esse longo caminho

Contemplando o cemitério dos mortos lançados ao mar 
Na demência dum louco do poder, caminhando impune para a frente, sem temer a justiça dos homens

É difícil sim, perdoar os carrascos

Esquecer as terras donde nos escorraçaram

As galeras transportando nossas avós para outros continentes

Lançando no mar as cargas humanas

Se os navios negreiros têm lastro em demasia, é difícil sim,

Esquecer todos esses anos de torturas e inundar o mundo

luz ${ }^{5}$ De paz e de amor, na hora fatal do ajuste de contas.

É difícil sim, mas um erro não justifica outro erro igual.

$\mathrm{Na}$ construção de um mundo novo à sombra das nossas terras maravilhosas, juramos não sofrer uma afronta igual Mas receber conscientes os ${ }^{6}$ amor onde há fraternidade Espalhando assim o grito potente da nossa apregoada selvajaria Mas essa hora tarde e os gritos do deserto espreitam

Por sobre as nossas cabeças encanecidas da longa espera

Mas os nossos sonhos hão-de abrir clareiras nos eternos luares

Dos nossos desertos assombrados.

Ao lermos o poema "Construir", temos a sensação de que ele é uma espécie de continuidade de "Passe", pois, ao contrário deste, o sujeito poético - também um "nós" - já se mostra consciente da própria identidade, de modo que sua reivindicação, agora, não é mais retirar o poder das mãos do colonizador, mas, conforme sinaliza desde o título, "Construir" "um mundo novo onde o amor campeia, unindo os homens/ de todas as terras".

"Construir" é um poema que, com os olhos baseados na esperança, se volta para o futuro, mas sem esquecer a injustiça vivenciada pelo colonizado no curso dos anos; ela está, segundo o sujeito poético, "Crucificada todos os dias na alma dos seus filhos". Tanto isso é verdade que há quatro anáforas (re)afirmativas - "É difícil sim" - para introduzir as (in)diferenças sociais ao longo dos trinta e três versos que constituem o poema e dentre as quais destacamos, só para exemplificar, a imagem do "pai esbofeteado/ Pelo despotismo dum tirano qualquer/ A irmã violada pelo mais forte, os irmãos morrendo nas minas/ Enquanto os argentários amontoam o oiro".

Ainda que a própria Alda Espírito Santo, em entrevista concedida a Michel Laban (2002, p. 100), qualifique a sua poesia como sendo "de solidariedade", tem razão Laura Cavalcante Padilha (2006, p. 21) quando afirma que se trata de "uma solidariedade aos

\footnotetext{
${ }^{5}$ Questionamos se não há um equívoco nesta edição da obra, pois nos parece que a palavra "luz" faz parte do verso anterior.

${ }^{6}$ Também aqui temos a impressão de haver um equívoco; seria mais adequado que o artigo estivesse no singular.
} 
iguais", posto responder a violência imprimida pelo colonizador com a violência do "fogo de sua fala". Nessa mesma linha, invocamos Frantz Fanon (1979, p. 193), para quem

o homem colonizado que escreve para seu povo deve, quando utiliza o passado, fazê-lo com o propósito de abrir o futuro, convidar à ação, fundar a esperança. Mas para garantir a esperança, para lhe dar densidade, é preciso participar da ação, engajar-se de corpo e alma no combate nacional.

Confrontando tais idéias com o poema "Construir", percebemos que, de fato, conforme o sujeito poético se vale das agruras do passado para impulsionar os seus pares para a "construção" do futuro, solidariza-se com os mesmos; concomitantemente, a violência dos versos cantados pelo sujeito poético coletivo - um "nós" -, em revide à violência dos atos praticados pelo colonizador, colabora para que um projeto de busca pela identidade nacional seja instalado.

Uma outra observação que não nos pode passar é que, da mesma forma que no poema de Noémia de Sousa, o par opositivo luminosidade versus obscuridade aparece bem demarcado também nesse de Alda Espírito Santo. Todavia, a simbologia, em "Construir", não é subversiva como em "Passe"; aqui, a luminosidade indicia, de fato, algo benéfico, como vemos nos dois versos finais: "Mas os nossos sonhos hão-de abrir clareiras nos eternos luares/ Dos nossos desertos assombrados". Notável é a intensidade de luz desejada pelo sujeito poético: não bastam os "luares", eles são reforçados com o adjetivo "eternos" e com o substantivo "clareiras", formando um conjunto de imagens que, justaposto aos "nossos sonhos", norteia a vontade de realizar a "construção de um mundo novo à sombra das nossas/ terras maravilhosas". Em contrapartida, o passado é referido como "nossos desertos assombrados", numa remissão às crueldades cometidas pelo colonizador.

Retomando a idéia do engajamento e da combatividade na poesia de Alda Espírito Santo, os versos livres e extensos que se aproximam da prosa e o emprego reiterado dos verbos de ação, já a começar pelo título do poema - "Construir" -, têm sua importância, pois, ao contrário do que se espera, o sujeito poético tece as malhas de uma revolta que não se ampara na luta armada, mas na edificação: "um erro não justifica outro erro igual".

Como vemos, tanto o poema "Passe" de Noémia de Sousa quanto o poema "Construir" de Alda Espírito Santo apontam para as (in)diferenças sociais e denunciam, cada um com suas características específicas, a situação colonial opressiva e violenta à que 
se opõe um sujeito poético coletivo - um "nós" - que, fazendo uso da voz ou do gesto, não se queda na inércia jamais.

\section{Referências bibliográficas}

FANON, Frantz. Os condenados da terra. Trad. José Laurênio de Melo. 2. ed. Rio de Janeiro: Civilização Brasileira, 1979.

LABAN, Michel. Encontro com Noémia de Sousa. In: Moçambique. Encontro com escritores. Porto: Fundação Eng. António de Almeida, 1998, v. 1, p. 243-346.

. Encontro com Alda Espírito Santo. In: São Tomé e Príncipe. Encontro com escritores. Porto: Fundação Eng. António de Almeida, 2002, v. 1, p. 61-104.

LARANJEIRA, Pires. A negritude africana de língua portuguesa. Porto: Edições Afrontamento, 1995.

LEITE, Ana Mafalda. Voz, origem, corpo, narração - poesia de Noémia de Sousa. In: Oralidades \& escritas nas literaturas africanas. Lisboa: Edições Colibri, 1998, p. 101-110.

MEMMI, Albert. Retrato do colonizado precedido pelo retrato do colonizador. Trad. Roland Corbisier e Mariza Pinto Coelho. 3. ed. Rio de Janeiro: Paz e Terra, 1989.

MOURÃO, Fernando. Memória dos anos cinqüenta. In: Mensagem. Lisboa: Editora ACEI, 1997, p. 125.

PADILHA, Laura Cavalcante. Silêncios rompidos. In: Novos pactos, outras ficções: ensaios sobre literaturas afro-luso-brasileiras. Porto Alegre: EDIPUCRS, 2002, p. 171-186.

. Uma voz insubordinada e solidária. In: MATA, Inocência (coord.). A poesia e a vida: homenagem a Alda Espírito Santo. Lisboa: Edições Colibri, 2006, p. 21-27.

PONTES, Roberto. Poesia insubmissa afrobrasilusa: estudo da obra de José Gomes Ferreira, Carlos Drummond de Andrade e Agostinho Neto. Fortaleza: EUFC; Rio de Janeiro: Oficina do Autor, 1999.

ROCHA, Edmundo. Angola. Contribuição ao estudo da génese do nacionalismo moderno angolano (periodo de 1950-1954) (testemunho e estudo documental). Lisboa: Edição do Autor, 2003.

SANTO, Alda Espírito. Cantos do solo sagrado. São Tomé e Príncipe: UNEAS, 2006. . O coral das ilhas. São Tomé e Príncipe: UNEAS, 2006a.

SILVA, Tomaz Tadeu da. A produção social da identidade e da diferença. In: SILVA, Tomaz Tadeu da (org.). Identidade e diferença: a perspectiva dos estudos culturais. 4. ed. Petrópolis: Vozes, 2005, p. 73-102.

SOUSA, Noémia de. Sangue negro. Maputo: AEMO, 2001. 
Nome do arquivo: DossieEricaAntunesPereira.doc

Pasta: $\quad$ C: $\quad$ Documents and Settings $\backslash$ Leila $\backslash$ Desktop

Modelo: $\quad$ C: $\quad$ Documents and Settings $\backslash$ Leila $\backslash$ Dados de aplicativos $\backslash$ Microsoft $\backslash$ Modelos $\backslash$ Normal.dot

Título: As (in)diferenças sociais nas vozes poéticas de Alda Espírito Santo e Noémia de Sousa

Assunto:

Autor: $\quad$ Microsoft Windows XP

Palavras-chave:

Comentários:

Data de criação: $\quad$ 1/6/2007 13:54:00

Número de alterações:5

Última gravação: $\quad$ 1/6/2007 14:19:00

Salvo por: José Carlos Siqueira

Tempo total de edição: 21 Minutos

Última impressão: $\quad$ 2/6/2007 13:19:00

Como a última impressão

Número de páginas: 9

Número de palavras: 3.278 (aprox.)

Número de caracteres: 17.703 (aprox.) 